\title{
Pediatric Barcelona Olfactory Test - 6 (pBOT-6): Validation of a Combined Odor Identification and Threshold Screening Test in Healthy Spanish Children and Adolescents
}

\author{
Mariño-Sánchez $\mathrm{F}^{1,2}$, Valls-Mateus $\mathrm{M}^{2,3}$, Fragola $\mathrm{C}^{1}$, de los Santos $\mathrm{G}^{1,4}$, Aguirre $\mathrm{A}^{1}$, Alonso J1' Valero J ${ }^{5}$, \\ Santamaría $\mathrm{A}^{1}$, Rojas Lechuga MJ ${ }^{2,3}$, Cobeta I1,4, Alobid I2,3,*, Mullol J2,3,* \\ 'Unidad de Rinología y Cirugía de Base de Cráneo, Servicio de Otorrinolaringología, Hospital Universitario Ramón y Cajal, Madrid, Spain \\ ${ }^{2}$ Immunoal-lèrgia Respiratòria Clínica i Experimental (IRCE), Institut d'Investigacions Biomédiques August Pi i Sunyer (IDIBAPS), Research Group \\ of Excellence 2017-SGR-1090 (Generalitat de Catalunya). Barcelona, Catalonia, Spain \\ ${ }^{3}$ Unitat de Rinologia i Clinica de I'Olfacte, Servei d'Otorinolaringologia, Hospital Clínic, Universitat de Barcelona, CIBERES. Barcelona, Spain \\ ${ }^{4}$ Universidad de Alcalá, Alcalá de Henares, Madrid, Spain \\ ${ }^{5}$ Departamento de Fisicoquimica, Facultat de Farmàcia, Universitat de Barcelona, Spain \\ *Both authors contributed equally to the manuscript with senior responsibilities.
}

J Investig Allergol Clin Immunol 2020; Vol. 30(6): 439-447

doi: 10.18176/jiaci.0451

\section{Abstract}

Background: Few odor tests have been developed for children.

Objectives: The aim of the present study was to develop and validate a simple and quick olfactory test to evaluate odor identification and threshold in a Spanish pediatric population.

Methods: The Pediatric Barcelona Olfactory Test- 6 (pBOT-6) consisted of a set of 6 odorants for a forced choice identification test and a 6-dilution phenyl ethyl alcohol geometric series for the threshold test. The pBOT-6 was compared with the Universal Sniff test (a validated international pediatric smell test) in 131 healthy Spanish volunteers aged 6-17 years. A Bland-Altman plot was used to determine the agreement between the 2 tests. Reliability was analyzed in 15 volunteers using the intraclass correlation coefficient. Normative data were obtained, and 8 children diagnosed with subjective loss of smell were tested for validation.

Results: The Bland-Altman analysis demonstrated a minimal bias of $-1.71 \%$ with upper and lower limits of agreement of $-31.1 \%$ and $27.6 \%$, respectively. The intraclass correlation coefficient was $0.83(95 \% \mathrm{Cl}, 0.6-0.96)$ for the identification test and $0.73(95 \% \mathrm{Cl}, 0.36-0.9)$ for the threshold test, with excellent and good consistency between measurements over time. Mean pBOT-6 scores were significantly higher in healthy volunteers than in patients with loss of smell. Discrimination between normosmia and loss of smell was achieved with a sensitivity of $96.9 \%$ and a specificity of $100 \%$.

Conclusions: pBOT-6 offers an effective and fast method that is useful in clinical routine to distinguish, with high sensitivity and specificity, between pediatric patients with normosmia and those with loss of smell.

Key words: Olfaction. Smell test. Pediatric. Children. Loss of smell.

\section{Resumen}

Antecedentes: Existen pocas pruebas de olfato para niños.

Objetivos: Desarrollar y validar una prueba de olfato simple y rápida para evaluar la identificación y el umbral olfativo en la población pediátrica española.

Métodos: El Pediatric Barcelona Olfactory Test-6 (pBOT-6) consiste en un set de 6 odorantes para la prueba de identificación forzada y una serie de 6 diluciones de feniletil alcohol para la prueba de umbral. El pBOT-6 se comparó con el Universal Sniff Test (una prueba de olfato pediátrica validada internacionalmente) en 131 voluntarios españoles sanos de entre 6 y 17 años. Se utilizó el método gráfico de Bland-Altman para determinar la concordancia entre las 2 pruebas. La fiabilidad se analizó en 15 voluntarios utilizando el coeficiente de correlación intraclase. Se obtuvieron los valores de normalidad y validó la prueba en 8 niños diagnosticados de pérdida subjetiva del olfato. Resultados: El método de Bland-Altman demostró un sesgo mínimo de $-1,71 \%$ con límites superior e inferior de acuerdo de $-31,1 \%$ y $27,6 \%$, respectivamente. El coeficiente de correlación intraclase fue de 0,83 (IC 95\%,0,6-0,96) para la prueba de identificación y 0,73 (IC 95\%, 0,36-0,9) para la prueba de umbral, con excelente y buena concordancia entre las mediciones a lo largo del tiempo. Las puntuaciones medias del pBOT-6 fueron significativamente más altas en voluntarios sanos que en pacientes con pérdida del olfato. Se obstuvo la discriminación entre normosmia y pérdida del olfato con una sensibilidad del $96,9 \%$ y una especificidad del $100 \%$.

Conclusiones: pBOT-6 ofrece un método eficaz y rápido que es útil en la práctica clínica para distinguir, con alta sensibilidad y especificidad, entre pacientes pediátricos con normosmia y aquellos con pérdida del olfato.

Palabras clave: Olfato. Prueba de olfato. Pediátrico. Niños. Pérdida del olfato. 


\section{Introduction}

Our sense of smell provides us with information on the surrounding environment $[1,2]$. Since olfactory function is linked to learning [3], smell disorders could be an important handicap in children's development.

Studies assessing smell dysfunction in children are scarce, even though several causes of olfactory dysfunction (eg, congenital anosmia, allergic rhinitis, head trauma, adenoidal hyperplasia, and turbinate enlargement) are common in this population [4-7].

Several odor identification tests have been developed in various countries for use in clinical practice, mainly in adults [8-11]. However, the nature of odor identification usually limits the use of olfactory tests to the country or region where they have been developed and validated.

The Barcelona Smell Test (BAST-24) [12] is widely used in Spain. However, it may not be adequate for children. It takes approximately 30 to 45 minutes to apply and requires a high level of concentration during the procedure. Therefore, it might be particularly challenging for children, who become tired more easily and have a shorter attention span than adults, thus potentially leading to considerable arbitrariness in their answers. Moreover, an odor identification score might vary with the child's verbal skills [13].

While specific smell tests have been created for children [14-17], they are more difficult to obtain and may not be suitable for very young patients. A new international odor identification test for children, the Universal Sniff Test (U-Sniff), was recently validated in 19 countries [18]. However, this test does not include a threshold test to complement the identification task for the assessment of sensorial dysfunction. A composite analysis of the components of olfaction, in particular odor thresholds, constitutes the most meaningful approach to human olfactory function $[19,20]$.

The objectives of the present study were to develop a simple and quick olfactory test that would be suitable for the evaluation of odor identification and threshold in a Spanish population aged 6-17 years and to assess the reproducibility and validation of the test.

\section{Materials and Methods}

\subsection{Study Population}

The study population comprised 131 Spanish healthy volunteers aged 6-17 years with a subjectively normal sense of smell. The participants were included from February to September 2016 at a tertiary care center. All children and adolescents were healthy volunteers of middle socioeconomic class. According to age, volunteers were stratified into 4 groups: 6-8, 9-11, 12-14, and 15-17 years.

The exclusion criteria were upper respiratory tract infection in the previous 2 weeks, known psychiatric or neurocognitive impairment, nasal inflammatory disorders, previous nasal surgery, diabetes mellitus, renal failure, or any other disease linked to olfactory dysfunction.

\subsection{Study Design}

The local ethics committee approved the study, and signed informed consent was obtained from the volunteer's legal guardians. Adolescents ( $\geq 12$ years old) gave their assent. Additionally, children $(<12$ years old) gave their oral assent.

Each volunteer was tested individually in a soundproofed, well-ventilated room with controlled humidity and temperature $\left(21-23^{\circ} \mathrm{C}\right)$. Individuals were tested simultaneously in both nostrils, first for identification and then for threshold.

In order to compare the results of our smell test with those of an already validated and standardized smell identification method in children, all volunteers were also tested using the U-Sniff Test [18].

Children were randomized to first undergo the Pediatric Barcelona Olfactory Test-6 (pBOT-6) or the U-Sniff test. The duration of each test was recorded.

A group of 15 children were tested in 3 separate sessions with a 2-week interval between examinations to evaluate test-retest reliability. We also included 8 children who had previously been assessed with the pediatric Smell Wheel Test [16]: 4 were diagnosed with isolated congenital anosmia (ICA), and 4 with partial loss of smell due to inflammatory causes ( 1 nasal polyposis in a patient with cystic fibrosis, 2 patients with adenoidal hyperplasia, and 1 patient with chronic rhinosinusitis without nasal polyps)

\subsection{Subjective Olfactometry}

\subsection{1. pBOT-6}

\subsubsection{Smell identification test}

Odorants were included in the test based on a comprehensive review of the main olfactory tests reported in the literature. From a list of more than 50 odors, a panel of experienced investigators selected the final odors to be incorporated in the test. To be selected, the odors had to be easily identifiable and recognizable by young Spanish children, as well as costeffective and easy to manufacture as chemical compounds (odorants).

Six odorants were selected for inclusion in the pBOT-6 (Table 1), as follows: 5 odors producing little or no trigeminal

Table 1. Odorants Selected for pBOT-6 Identification Test With Their Chemical Compounds and Descriptors Used for the Forced Choice Task

\begin{tabular}{|c|c|c|}
\hline Odorant & Chemical Compound & Descriptors \\
\hline Banana & Isoamyl acetate & $\begin{array}{l}\text { Banana, grass, onion, } \\
\text { coffee }\end{array}$ \\
\hline Chocolate & Pyrazines & $\begin{array}{l}\text { Pineapple, tangerine, } \\
\text { soap, chocolate }\end{array}$ \\
\hline Vinegar & Acetic acid & $\begin{array}{l}\text { Strawberry, vinegar, } \\
\text { fish, poop }\end{array}$ \\
\hline Lemon & Citral & $\begin{array}{l}\text { Lemon, smoke, } \\
\text { popcorn, cheese }\end{array}$ \\
\hline Mint & Menthol & $\begin{array}{l}\text { Gasoline, peach, mint, } \\
\text { tomato }\end{array}$ \\
\hline Flower & Phenethyl alcohol & $\begin{array}{l}\text { Honey, flower, apple, } \\
\text { cookies }\end{array}$ \\
\hline
\end{tabular}


stimulation (banana, chocolate, lemon, mint, and flower/ rose); and 1 odor producing strong trigeminal stimulation (vinegar). Hermetic glass containers were designed to contain the different odorants (Figure 1A), according to the recommendations of the Meeting of the German Society for Otorhinolaryngology [10].

Volunteers were requested to identify the odor from 4 given image descriptors (Table 1) labeled with their names, which were shown before presentation of the odorant on a computer screen using an Excel spreadsheet (Microsoft Office Professional Plus 2013). Each odorant jar was presented 1 at a time by holding it $1 \mathrm{~cm}$ in front of the nose for 2-3 seconds, although there was no contact with the observer's finger or the volunteer's face. If uncertain, children were allowed to smell the odorant up to 3 times. The test was repeated for each of the 6 odors. The observer clicked on the label selected by the volunteer, and a macro created in Microsoft Excel changed the screen to the image descriptors of the next odor and automatically calculated the scores (Figure 1B).

The sum of correct identification answers (0-6/6) was used to obtain the identification score (IS), which was also expressed as a percentage of the total number of odorants presented $(0 \%-100 \%)$.

\subsubsection{Smell threshold test}

Phenyl ethyl alcohol (PEA, rose scent) was used for the threshold test, with 6 dilutions of a geometric series presented in sniff bottles containing $20 \mathrm{~mL}$ of solution (Figure 1C). The solvent for PEA was propylene glycol.

The detection threshold measurement was obtained using a single ascending forced choice method widely used in Japan [21,22], beginning with the lowest concentration (Bottle 6, 0.00002\%) and increasing the PEA concentration gradually (Bottle 5, 0.0002\%; Bottle 4, 0.002\%; Bottle 3, $0.02 \%$; Bottle 2, 0.2\%; and Bottle 1, 2\%). With each bottle, participants were asked to respond "yes" or "no" to the question "Do you smell anything?" The dilution step at which the odorant stimulus was first detected was used to define the detection threshold. Before testing, volunteers were instructed to say "yes" only when they were certain they had detected the odor, but they were not asked to identify it. If unsure,

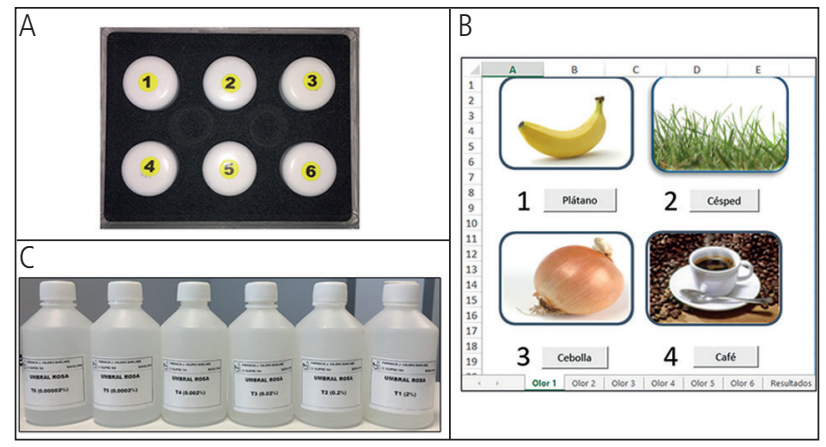

Figure 1. Pediatric Barcelona Olfactory Test with the 6 odorant glass jars (A) for odor identification, a computer screen capture of image descriptors, the labels used for the forced choice identification task (B) for banana, and the 6 plastic sniff bottles (C) with phenyl ethyl alcohol dilutions for the threshold detection task. The original descriptor labels in Spanish were plátano (banana), césped (grass), cebolla (onion), café (coffee), umbral rosa (rose threshold). the subjects were instructed not to guess. The PEA threshold measurement was reported on a numeric scale corresponding to the number of the bottle (1 to 6 ) detected by the volunteer; this defined the volunteer's threshold score (TS). If the volunteer was not able to detect the most concentrated dilution (Bottle 1, $2 \%$ ), the number " 0 " was assigned.

\subsubsection{Universal-Sniff test for children (U-Sniff)}

pBOT-6 was compared with the U-sniff test, which contains 12 odor items presented as pen-like "sniffin' sticks", administered in a 4-answer forced choice model using an image and name of odors, with an IS of 0 to $12(0 \%-100 \%)$ [18].

\subsection{Statistical Analysis}

Data were managed and the statistical analysis was performed using Epiinfo for Windows (Epiinfo 7.1.5; Atlanta, USA) and MedCalc for Windows (MedCalc version 15, Ostend, Belgium; http://www.medcalc.org). A Bartlett test was performed to evaluate the homogeneity of variance.

Frequencies and mean (SD) were calculated for the demographic and clinical characteristics of the participants. Analysis of variance was used to analyze the distribution of participants and differences in smell outcomes according to sex and age. $P \leq .05$ was considered statistically significant.

A Bland-Altman plot was used to compare pBOT-6 with the U-Sniff test. For each IS, the average of the pBOT-6 and U-Sniff tests were calculated and plotted against the difference between the 2 measurements. The limits of agreement were defined as the mean difference $\pm 1.96 \mathrm{SD}$ of difference. The $95 \% \mathrm{CI}$ of the limits of agreement was used to define agreement between the 2 smell tests [23].

The correlation between smell scores and age was assessed using a linear regression analysis. Additionally, a 2-sample Mann-Whitney test was used to analyze differences in IS and TS between the age groups and between healthy volunteers and patients with loss of smell.

Reliability over time (test-retest) was analyzed using the intraclass correlation coefficient (ICC). The strength of the ICC was interpreted according to Shrout and Fleiss [24] as follows: poor, $<0.40$; fair to good, $0.40-0.75$; and excellent $>0.75$. Using the formula of Walter et al [25], we calculated that a minimum sample size of 13 healthy children with 3 observations per child would be required to achieve statistical significance for an $\alpha$ value set at 0.05 and with a minimum power of $80 \%$.

In order to validate the test to differentiate participants with a normal smell function from those with partial or total smell

Table 2. Demographic Data

\begin{tabular}{lccc}
\hline Age Group & $\begin{array}{c}\text { Females, } \\
\text { No. (\%) }\end{array}$ & $\begin{array}{c}\text { Males, } \\
\text { No. (\%) }\end{array}$ & $P$ Value $^{\mathrm{a}}$ \\
\hline 6-8 years & $53(61)$ & $34(39)$ & \\
9-11 years & $12(60)$ & $8(40)$ & \\
12-14 years & $8(50)$ & $8(50)$ & $>.05$ \\
15-17 years & $4(50)$ & $4(50)$ & \\
Total & $77(59)$ & $54(41)$ &
\end{tabular}

${ }^{a}$ Analysis of variance for comparison between males and females. 
Table 3. Demographic and Clinical Data of Patients With Loss of Smell

\begin{tabular}{lccccc}
\hline Patient & Age, $y$ & Sex & Cause of Loss of Smell & pBOT-6 IS & pBOT-6 TS \\
\hline 1 & 8 & Male & Adenoid hyperplasia & 3 & 1 \\
2 & 6 & Male & Adenoid hyperplasia & 3 & 2 \\
3 & 14 & Male & Cystic fibrosis, CRSwNP & 3 & 3 \\
4 & 12 & Female & CRS & 2 & 0 \\
5 & 6 & Male & ICA & 1 & 0 \\
6 & 8 & Female & ICA & 0 & 0 \\
7 & 6 & Female & ICA & 0 & 0 \\
8 & 10 & Male & ICA & & 0
\end{tabular}

Abbreviations: CRS, chronic rhinosinusitis; CRSwNP; chronic rhinosinusitis with nasal polyps; ICA, isolated congenital anosmia; pBOT-6 IS, Pediatric Barcelona Olfactory Test identification score; pBOT-6 TS, Pediatric Barcelona Olfactory Test threshold score.

loss, the 10th percentile was used as a cut-off point, based on pre-existing tests $[8,12,26]$. A receiver operator characteristics (ROC) curve analysis was performed in conjunction with the Youden index to define the highest sensitivity and specificity of pBOT-6. A group of 8 children with loss of smell diagnosed by the smell wheel test [16] were also assessed for purposes of validation.

According to a sample size calculation made by Hugh et al [17] ( $P$ value of .05 , power of 0.80 , clinically significant difference of 1.86 , and SD of 1.63), 8 participants were required per age group. However, more volunteers aged 6-8 years were recruited in order to validate the test in the youngest children, who may be more unfamiliar with the odors.

\section{Results}

\subsection{Demographic Characteristics}

The study population comprised 131 healthy volunteers (mean [SD] age, 9 [2.6] years; female 58\%). Most participants were children aged 6-8 years. Age groups were homogeneous in terms of sex (Table 2).

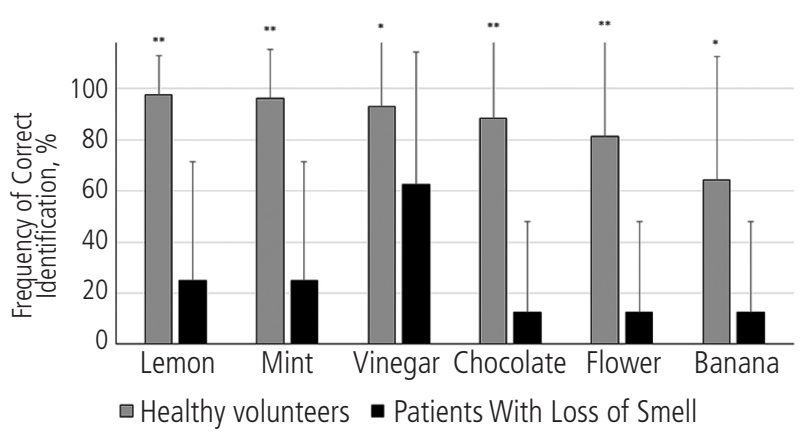

Figure 2. Frequency of correct odor identification (\%) in healthy volunteers (gray columns) and patients with olfactory dysfunction (black columns). An analysis of variance test was performed, and the difference between healthy volunteers and patients with loss of smell was evaluated. **, $P<.001 ; *{ }^{*} P<.01$.
All volunteers understood the task and were able to perform both smell tests. The mean duration of pBOT-6 (identification + threshold) was $2.33(0.44)$ minutes. The mean duration of the U-Sniff test was $2.55(0.57)$ minutes. The mean pBOT-6 total IS was $87.5(13.6 \%)$. Figure 2 displays the mean IS for each odor. Lemon was the most commonly identified odor, and banana the least frequently identified. The mean pBOT-6 IS was $88(14.7 \%)$ for girls and $86.7(11.8 \%)$ for boys $(P=.5)$. The mean TS was 3.1 (1.2) for girls and $3(1)$ for boys $(P=.6)$

Additionally, 8 children with loss of smell (total or partial) were included for test validation (Table 3). Odor identification scores were significantly lower for patients with loss of smell compared with healthy volunteers, although this difference was less pronounced for vinegar odor (Figure 2).

\subsection{Agreement Between BOT-6 and U-Sniff Test}

Bland-Altman analysis demonstrated a minimal bias of $-1.71 \%$, with an upper and lower limit of agreement of $-31.1 \%$

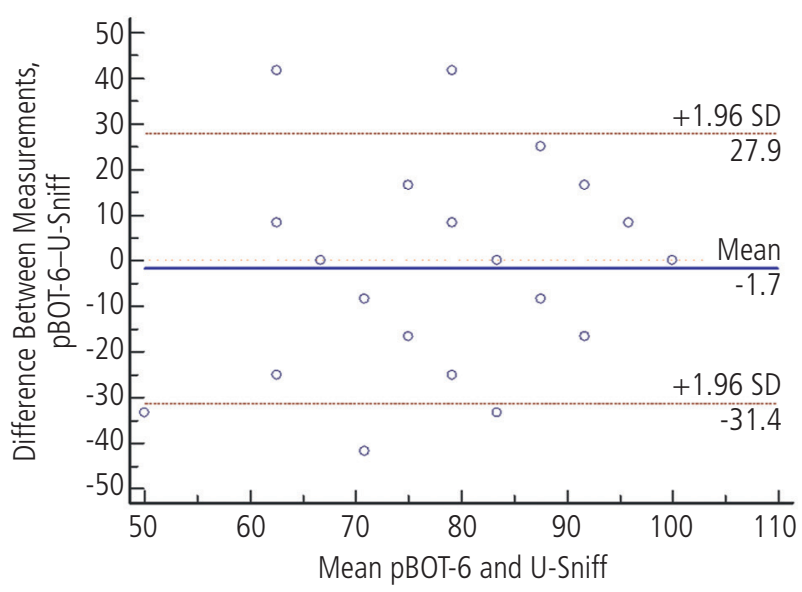

Figure 3. Bland-Altman plot comparison between the pBOT-6 and the $U$-Sniff tests within $95 \%$ limits of agreement. The $x$ axis represents the average of the identification score values (pBOT-6 + U-Sniff) and the $y$ axis represents the difference between the values (pBOT-6 - U-Sniff) pBOT-6 indicates Pediatric Barcelona Odor Test - 6; U-Sniff, Universa Sniff Test; IS, identification score. 
A

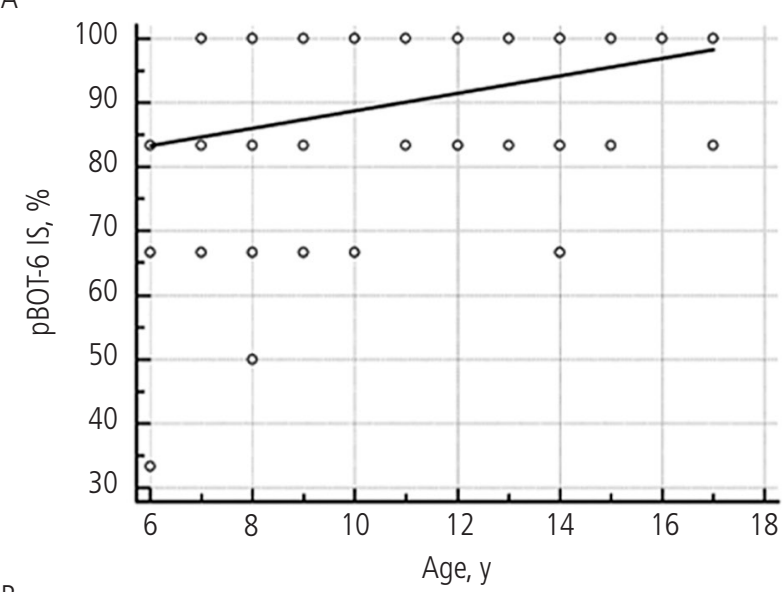

B
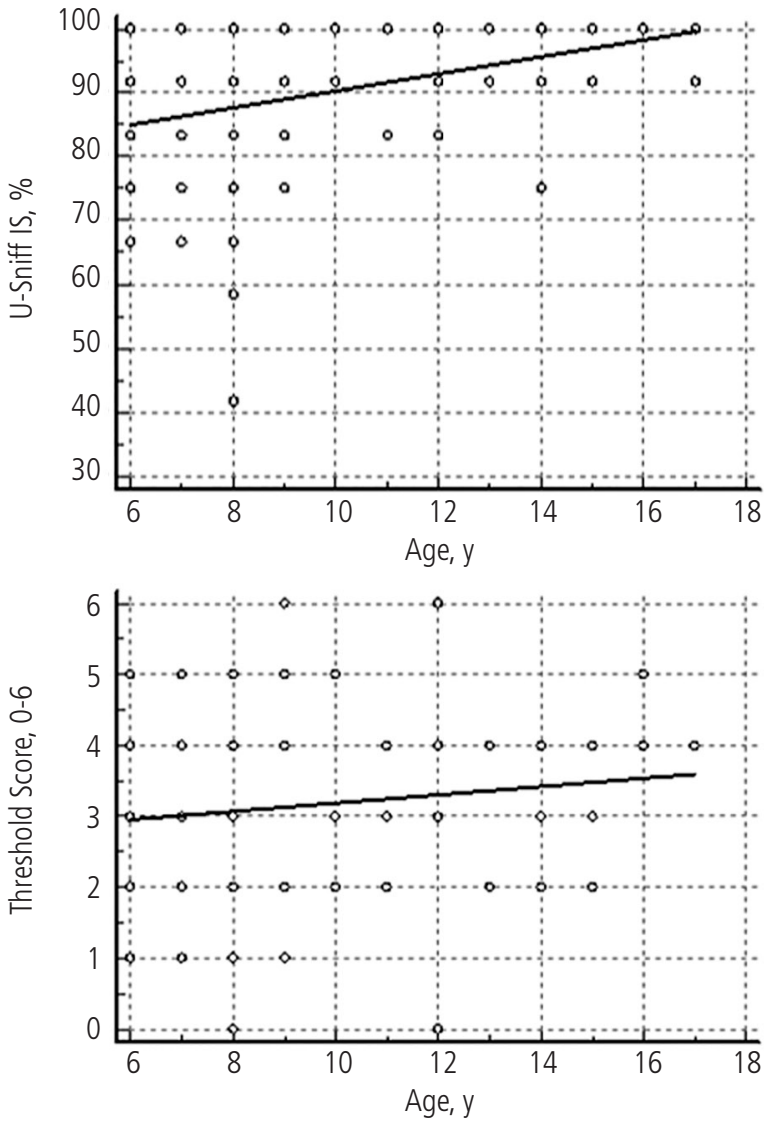

Figure 4. Linear regression analysis of the correlation between age and the pBOT-6 identification score (A), the U-Sniff identification score (B), and the pBOT-6 threshold score (C). pBOT-6 indicates Pediatric Barcelona Odor Test - 6; U-Sniff, Universal Sniff Test.

and $27.6 \%$, respectively. After calculating the mean difference and the SD of the difference, we would expect most of the differences to lie between the limits of agreement. Hence, according to the Bland-Altman method, correlation and agreement between pBOT-6 and the U-Sniff test were good (Figure 3).

Figures $4 \mathrm{~A}$ and $4 \mathrm{~B}$ show a moderate correlation between pBOT-6 IS and age $(\mathrm{r}=0.26 ; 95 \% \mathrm{CI}, 0.09-0.41 ; P<.05)$ and between U-Sniff IS and age $(\mathrm{r}=0.31 ; 95 \% \mathrm{CI}, 0.14-0.45 ; P<.001)$.
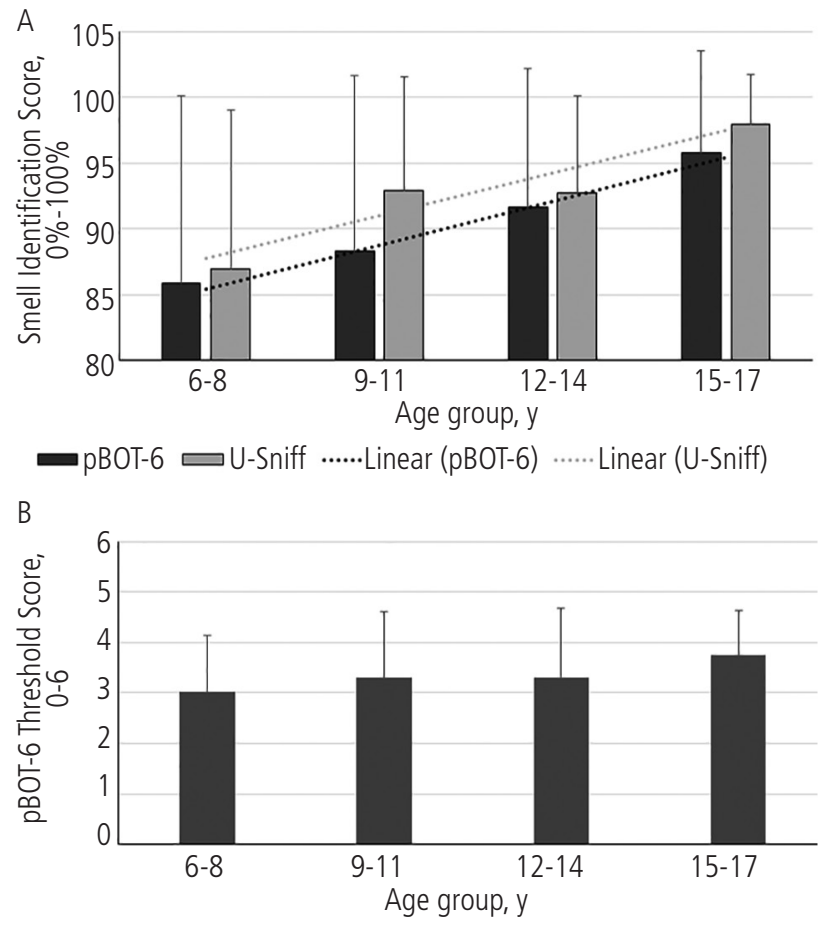

Figure 5. Mean pBOT-6 (dark gray column) and U-Sniff test (light gray column) smell identification scores (A) and mean threshold scores (B) according to age group, where the black dotted line is the pBOT-6 tendency line and the gray dotted line the U-Sniff tendency line. pBOT-6 indicates Pediatric Barcelona Odor Test - 6; U-Sniff, Universal Sniff Test.

Figure 4C shows no significant correlation between PEA threshold score and age $(\mathrm{r}=0.14 ; 95 \% \mathrm{CI},-0.04$ to $0.29 ; P>.05)$.

Figure 5A shows a significant increase in IS in the older age groups $(P<.001)$, with no significant differences between the U-Sniff and pBOT-6 tests. Figure 5B shows no differences $(P>.05)$ in TS between the age groups.

\subsection{Reliability (Test-Retest)}

Analysis of olfactory scores at weeks 0,2 , and 4 in 15 volunteers (Table 4 ) revealed that the ICC was $0.83(95 \% \mathrm{CI}$, $0.6-0.96)$ for the pBOT-6 IS and $0.73(95 \% \mathrm{CI}, 0.36-0.9)$ for the pBOT-6 TS, indicating excellent and good consistency between measurements over time, respectively.

\subsection{Normative Values}

To separate normosmia from olfactory dysfunction, we applied the 10th percentile cut-off to our data sample for the IS at each age group. According to the 10th percentile, an IS of 4/6 in children aged 6-8 and 9-11 years and an IS of 5/6 in children aged 12-14 and 15-17 years is considered normosmic. Therefore, scores below these values can be considered loss of smell. Regarding the PEA threshold test, the 10th percentile cut-off defined normosmia as a TS of $2 / 6$ for all age groups.

\subsection{Validation}

A group of 8 children diagnosed with subjective smell loss ( 4 children with ICA and 4 children with hyposmia caused by inflammatory conditions) were analyzed (Table 3 ). 
Table 4. Test-Retest Reliability Analysis: Volunteer Data and Smell Scores

\begin{tabular}{|c|c|c|c|c|c|c|c|c|}
\hline \multirow[t]{2}{*}{ Subject } & \multirow[t]{2}{*}{ Age } & \multirow[t]{2}{*}{ Sex } & \multicolumn{2}{|c|}{ Week 0} & \multicolumn{2}{|c|}{ Week 2} & \multicolumn{2}{|c|}{ Week 4} \\
\hline & & & IS (0-6) & TS (0-6) & IS (0-6) & TS (0-6) & IS (0-6) & TS (0-6) \\
\hline 1 & 14 & Female & 4 & 4 & 4 & 4 & 5 & 4 \\
\hline 2 & 12 & Female & 6 & 3 & 6 & 3 & 6 & 4 \\
\hline 3 & 14 & Male & 5 & 3 & 5 & 4 & 6 & 4 \\
\hline 4 & 8 & Male & 6 & 4 & 6 & 4 & 6 & 4 \\
\hline 5 & 12 & Female & 5 & 3 & 5 & 4 & 6 & 4 \\
\hline 6 & 14 & Female & 6 & 4 & 6 & 4 & 6 & 4 \\
\hline 7 & 7 & Male & 6 & 3 & 6 & 2 & 6 & 3 \\
\hline 8 & 7 & Male & 5 & 3 & 6 & 3 & 6 & 2 \\
\hline 9 & 7 & Male & 5 & 3 & 6 & 4 & 6 & 3 \\
\hline 10 & 7 & Male & 6 & 4 & 6 & 4 & 6 & 3 \\
\hline 11 & 7 & Male & 6 & 3 & 6 & 3 & 6 & 4 \\
\hline 12 & 7 & Male & 6 & 3 & 6 & 3 & 6 & 3 \\
\hline 13 & 7 & Male & 5 & 4 & 5 & 4 & 6 & 4 \\
\hline 14 & 7 & Female & 6 & 3 & 6 & 3 & 6 & 3 \\
\hline 15 & 7 & Female & 5 & 3 & 6 & 3 & 6 & 3 \\
\hline
\end{tabular}

Abbreviations: IS, identification score; TS, threshold score.
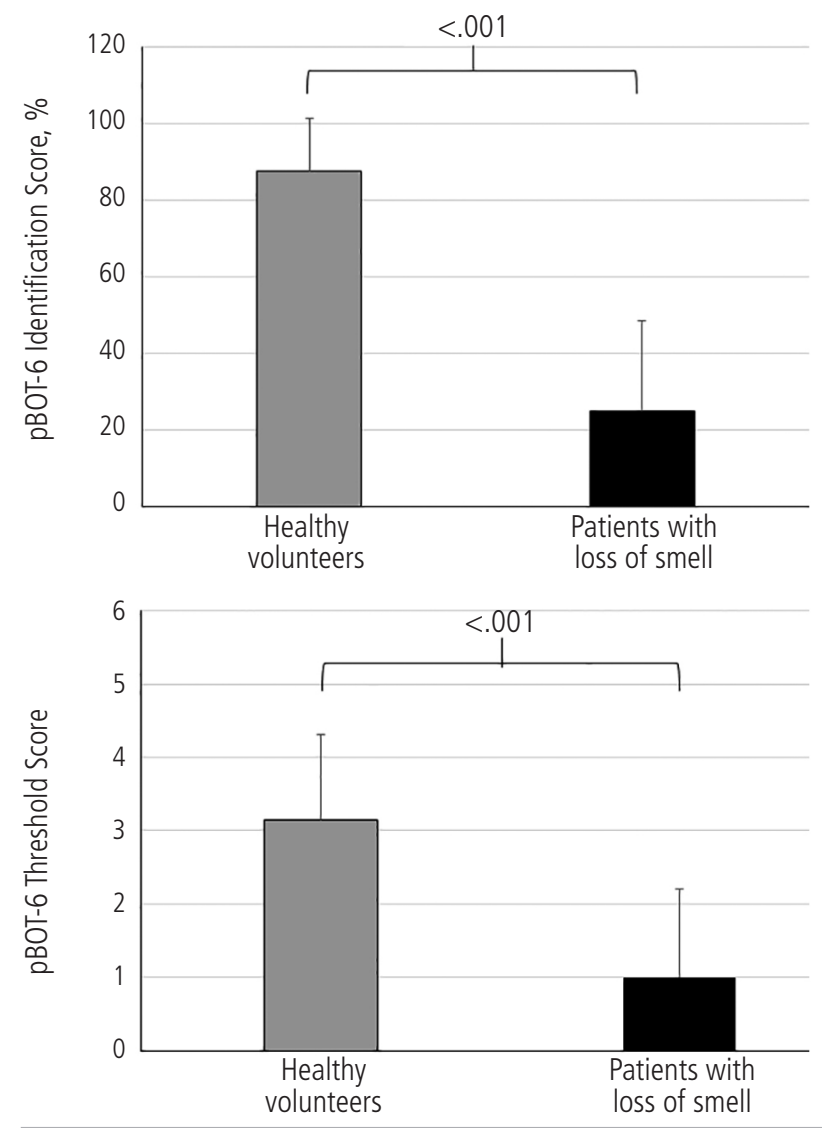

Figure 6. Two-sample Mann-Whitney test-based comparison of mean pBOT-6 identification score (A) and threshold score (B) between healthy volunteers (gray columns) and patients with loss of smell (black columns). pBOT-6 indicates Pediatric Barcelona Odor Test -6 .

The 4 patients included with partial loss of smell had a very low Smell Wheel test IS $(<4 / 11)$. None of the 4 patients with total smell loss (ICA) were able to detect or identify any of the Smell Wheel scratch and sniff odorants.

Mean pBOT-6 IS (Figure 6A) and TS (Figure 6B) were significantly higher in healthy volunteers than in patients with loss of smell. By using the highest Youden index, a sensitivity of $96.9 \%$ and a specificity of $100 \%$ to confirm a normal sense of smell were reached when a cut-off of $\geq 4 / 6$ points in IS was used. For the PEA threshold test, a sensitivity of $66.4 \%$ and a specificity of $87.5 \%$ to confirm a normal sense of smell were reached when a cut-off of $\geq 2 / 6$ points in TS was used.

\section{Discussion}

We developed and validated the pBOT- 6 smell identification and threshold test for children aged 6-17 years. This is the first smell test designed specifically for children to include a threshold test. Normative values for the healthy Spanish population were determined, and the reliability of the test was corroborated. All participants, including children as young as 6 years old, were able to understand and complete the test.

Bland-Altman analysis showed a significant correlation and agreement between the pBOT-6 and U-Sniff tests. Additionally, ICC values were consistent between measurements of pBOT6 identification and threshold tests over time. Moreover, normative values showed high sensitivity and specificity for diagnosis of loss of smell in children with ICA or inflammatory conditions associated with hyposmia.

Performance of both the U-Sniff and the pBOT-6 identification tests correlated and improved with age. This is consistent with previous studies demonstrating age-related 
increases in children's IS [14,17,18,27]. However, although we observed a tendency toward a better TS with age, the differences did not reach statistical significance. A previous study evaluated the olfactory threshold in children using a modified "Sniffin' Sticks" threshold test [20] and reported an increase in TS with age. However, the authors used a 3-alternative, forced choice test, which might take longer and requires a higher level of concentration, thus making it difficult for young children to perform adequately. In pBOT-6, we used a single ascending non-forced choice method. Our approach comprises a fast and very easy method for young children in which they are asked to detect, but not identify, an odorant. These results are in line with those of other studies that found no odor threshold differences between children and young adults $[1,28]$, suggesting that the ability to identify odors is related to perceptual learning with age. However, this cognitive ability does not extend to smell threshold detection, which is purely sensorial and therefore not affected by experience $[19,29]$. The importance of using a threshold test lies in the fact that a composite analysis of several components of olfaction provides a more comprehensive approach to olfactory function than smell identification alone, thus facilitating diagnosis of early stages of hyposmia [19].

It is well known that women outperform men in olfactory tasks [30,31]. However, sex difference in smell function in children is controversial. Some studies have reported that girls outperform boys $[13,15,18]$. Nevertheless, in accordance with other studies $[14,16,32,33]$, we found no sex differences in pBOT-6 IS and TS. As pBOT-6 was designed to be a simple, quick, and easy-to-perform screening test, it might not be sufficient to detect subtle sex differences. Furthermore, some studies show that the superiority of the female smell function decreases when men are provided with some help in the retrieval of odor names (pictures and labels in pBOT-6) [32].

Healthy volunteers showed higher pBOT-6 identification scores than patients with loss of smell for all odorants, although this difference was less noticeable for acetic acid odorant (vinegar). Some children with olfactory loss may be able to detect vinegar owing to its marked ability to stimulate trigeminal receptors [34]. Acetic acid has been described as a trigeminally potent chemical stimulus [35]. It stimulates a specific trigeminal receptor (TRPV1), even at very low concentrations, leading to a tingling sensation, which in higher concentrations becomes sharp, burning, and even painful [36].

Some pediatric odor identification tests have been designed to distinguish between normosmia and olfactory dysfunction [14-16,18]. However, odor identification differs significantly across countries [18]. Furthermore, performance relies on prior exposure to and familiarity with the odors presented, which may differ across cultures [37,38]. This limitation is particularly relevant for the pediatric population, where experience, semantic memory, and verbal skills affect proficiency in odor tasks. pBOT-6 was developed specifically for Spanish children, as a short, easy-to-perform olfactory screening test for use in daily clinical practice. Total IS was near $88 \%$, comparable with results for other smell tests developed for children, including NIH-Toolbox [39] (72\%), Smell Wheel [16] (70\%-90\%), and U-Sniff [18] (69\%-93\%).

When compared with the U-Sniff test, which was recently validated in various countries [18], pBOT-6 showed good correlation and agreement according to the Bland-Altman plot. The time required to perform the combined identification and threshold test was less than 3 minutes, which is similar to the duration of the U-Sniff identification test alone. The main advantage of the rapidity of pBOT-6 is that young children are able to maintain attention, thus decreasing the probability of randomness in their responses. Additionally, the test can be used as part of the standard in-office clinical assessment.

We believe the U-Sniff test is an excellent tool for evaluating olfaction in Spanish children. pBOT-6 is also a fast screening tool that is feasible for use in daily clinical practice. Children with loss of smell screened by pBOT- 6 can be further studied and diagnosed with the U-Sniff test and the PEA threshold test to complement assessment of olfactory function.

Test-retest pBOT-6 ICC values showed excellent consistency (0.8) and good consistency (0.7), respectively, in the identification and threshold measurements over time. Similar levels of reliability using the Pearson correlation have been noted in the Smell Wheel test $(r=0.7)$ [16] and U-Sniff test $(\mathrm{r}=0.83)$ [18]. However, pBOT-6 was more reliable than other pediatric tests such as the Sniffin' kids [14] ( $\mathrm{r}=0.44)$ and the NIH-Toolbox [39] ( $\mathrm{r}=0.45)$.

Only 3 pediatric smell identification tests included patients with olfactory dysfunction for validation during test development $[14,15,18]$. Although we included only 8 children diagnosed with loss of smell in the present study, children with ICA and sinonasal inflammatory disorders achieved significantly lower pBOT-6 IS and TS than healthy volunteers. Additionally, Youden index cut-off points (4/6 for IS and 2/6 for TS) made it possible to differentiate normosmia from smell loss, with high levels of sensitivity and specificity. These cut-off points coincided with the 10th percentile values, which are frequently used to separate normal from reduced sense of smell in olfactory testing $[8,14,15,18,39]$.

\subsection{Limitations}

Our study is subject to a series of limitations. First, the number of odorants used for the identification task might have been insufficient to accurately characterize smell function and define the severity of hyposmia. However, we decided to include only 6 odorants in order to maintain the children's attention span for as long as possible and to be able to use the test as a screening tool in daily clinical practice. Highly specific, brief smell identification tests (fewer than 6 items) have been developed to identify anosmia in adults [40-42]. Richman et al [43] validated a rapid test (5 microencapsulated odorants) based on the "scratch and sniff" technique in a large population of healthy children and adolescents, although they did not study the efficacy of the test in children with olfactory dysfunction. In the present study, pBOT-6 was highly sensitive and specific for diagnosis of olfactory dysfunction in 8 children with well-known causes of loss of smell. However, patients with loss of smell were initially evaluated using the Smell Wheel test [16], which has no normative/reference values published to date. Therefore, the difference between partial and total loss of smell was initially based on the patient's subjectivity and the parents' opinion. A much larger sample of such children should be evaluated with the test to characterize its efficacy for evaluating olfactory ability. Second, we did not 
conduct any cognitive tests. Hence, the influence of cognition on the ability to identify odors was not assessed in the current study. Third, odorants were selected based on the experience of participating researchers and, consequently, other odor items may also have been appropriate for inclusion. Fourth, our study lacks objective smell measurements. Although objective smell tests, such as odor-evoked response potentials and functional magnetic resonance imaging have been used in olfaction research, they are expensive, and their clinical use in humans has been limited to specialized smell and taste clinics. Fifth, this is the first study to use this olfactory threshold test in children. Therefore, it would be necessary to validate the test by correlating it with a previously validated pediatric threshold test. However, to the best of our knowledge, there are no odor detection threshold tests specifically designed for children in the literature. Few adult odor threshold tests have previously been used in the pediatric population. The Lyon Clinical Olfactory Test [13] and the "Sniffin' Sticks" olfactory threshold test [20] seem suitable and reliable for children and adolescents. However, these tests were developed in a specific country with country-specific odors that may not be suitable for Spanish children.

\section{Conclusions}

With the 6-item odor identification test and the 6-dilution odor threshold tests, we propose a valid and reliable tool, pBOT-6, to rapidly assess olfactory function in Spanish children and adolescents. pBOT- 6 is efficient and fast in clinical practice and can distinguish, with high sensitivity and specificity, between pediatric patients with normosmia and those with partial loss of smell (hyposmia) or total loss of smell (anosmia).

\section{Funding}

The authors declare that no funding was received for the present study.

\section{Conflicts of Interest}

The authors declare that they have no conflicts of interest.

\section{References}

1. Hummel T, Bensafi M, Nikolaus J, Knecht M, Laing DG, Schaal B. Olfactory function in children assessed with psychophysical and electrophysiological techniques. Behav Brain Res. 2007; 180(2):133-8.

2. Hummel T, Whitcroft $K L$, Andrews $P$, Altundag A, Cinghi $C$, Costanzo RM, et al. Position paper on olfactory dysfunction. Rhinol Suppl. 2017;54(26):1-30.

3. Li W, Luxenberg E, Parrish T, Gottfried JA. Learning to smell the roses: experience-dependent neural plasticity in human piriform and orbitofrontal cortices. Neuron. 2006;52(6):1097-108.

4. Langdon C, Guilemany JM, Valls M, Alobid I, Bartra J, Davila I, et al. Allergic rhinitis causes loss of smell in children: The OLFAPEDRIAL study. PediatrAllergy Immunol. 2016;27(8):86770.
5. Marino-Sanchez F, Valls-Mateus M, Haag O, Alobid I, Bousquet J, Mullol J. Smell loss is associated with severe and uncontrolled disease in children and adolescents with persistent allergic rhinitis. J Allergy Clin Immunol Pract. 2018;6(5):1752-5.e3.

6. Bousquet J, VandenPlas O, Bewick M, Arnavielhe S, Bedbrook A, Murray $R$, et al. The Work Productivity and Activity Impairment Allergic Specific (WPAl-AS) Questionnaire Using Mobile Technology: The MASK Study. J Investig Allergol Clin Immunol. 2018;28(1):42-4.

7. Del Cuvillo A, Sastre J, Colas C, Navarro AM, Mullol J, Valero A. Adaptation to Spanish and validation of the Rhinitis Control Assessment Test (RCAT) questionnaire. J Investig Allergol Clin Immunol. 2020;30(3):175-81.

8. Doty RL, Shaman P, Dann M. Development of the University of Pennsylvania Smell Identification Test: a standardized microencapsulated test of olfactory function. Physiol Behav. 1984;32(3):489-502.

9. Cain WS. Bilateral interaction in olfaction. Nature. 1977;268(5615):50-2.

10. Kobal G, Hummel T, Sekinger B, Barz S, Roscher S, Wolf S. "Sniffin' sticks": screening of olfactory performance. Rhinology. 1996;34(4):222-6.

11. Briner HR, Simmen D. Smell diskettes as screening test of olfaction. Rhinology. 1999;37(4):145-8.

12. Cardesin A, Alobid I, Benitez P, Sierra E, de Haro J, BernalSprekelsen M, et al. Barcelona Smell Test - 24 (BAST-24): validation and smell characteristics in the healthy Spanish population. Rhinology. 2006;44(1):83-9.

13. Monnery-Patris S, Rouby C, Nicklaus S, Issanchou $S$. Development of olfactory ability in children: sensitivity and identification. Dev Psychobiol. 2009;51(3):268-76.

14. Schriever VA, Mori E, Petters W, Boerner C, Smitka M, Hummel T. The "Sniffin' Kids" test--a 14-item odor identification test for children. PLoS One. 2014;9(6):e101086.

15. Richman RA, Post EM, Sheehe PR, Wright HN. Olfactory performance during childhood. I. Development of an odorant identification test for children. J Pediatr. 1992;121(6):90811.

16. Cameron EL, Doty RL. Odor identification testing in children and young adults using the smell wheel. Int J Pediatr Otorhinolaryngol. 2013;77(3):346-50.

17. Hugh SC, Siu J, Hummel T, Forte V, Campisi P, Papsin BC, et al. Olfactory testing in children using objective tools: comparison of Sniffin' Sticks and University of Pennsylvania Smell Identification Test (UPSIT). J Otolaryngol Head Neck Surg. 2015:44:10.

18. Schriever VA, Agosin E, Altundag A, Avni $H$, Cao Van $H$, Cornejo $C$, et al. Development of an International Odor Identification Test for Children: The Universal Sniff Test. J Pediatr. 2018;198:265-72.e3.

19. Lotsch J, Reichmann H, Hummel T. Different odor tests contribute differently to the evaluation of olfactory loss. Chem Senses. 2008;33(1):17-21.

20. Gellrich J, Stetzler C, Oleszkiewicz A, Hummel T, Schriever VA. Olfactory threshold and odor discrimination ability in children - evaluation of a modified "Sniffin' Sticks" test. Sci Rep. 2017;7:1928.

21. Takagi S. Olfactory Tests. In: Takagi S, editor. Human olfaction. Tokyo: University of Tokyo Press, 1989; 35-71. 
22. Tsukatani T, Miwa T, Furukawa M, Costanzo RM. Detection Thresholds for Phenyl Ethyl Alcohol Using Serial Dilutions in Different Solvents. Chemical Senses. 2018;28(1):2532.

23. Stockl D, Rodriguez Cabaleiro D, Van Uytfanghe $K$, Thienpont LM. Interpreting method comparison studies by use of the bland-altman plot: reflecting the importance of sample size by incorporating confidence limits and predefined error limits in the graphic. Clin Chem. 2004;50(11):2216-8.

24. Shrout PE, Fleiss JL. Intraclass correlations: uses in assessing rater reliability. Psychol Bull. 1979;86(2):420-8.

25. Walter SD, Eliasziw M, Donner A. Sample size and optimal designs for reliability studies. Stat Med. 1998;17(1):101-10.

26. Cain WS, Gent JF, Goodspeed RB, Leonard G. Evaluation of olfactory dysfunction in the Connecticut Chemosensory Clinical Research Center. Laryngoscope. 1988;98(1):83-8.

27. van Spronsen E, Ebbens FA, Fokkens WJ. Olfactory function in healthy children: normative data for odor identification. Am J Rhinol Allergy. 2013;27(3):197-201.

28. Cain WS, Stevens JC, Nickou CM, Giles A, Johnston I, Garcia-Medina MR. Life-span development of odor identification, learning, and olfactory sensitivity. Perception. 1995;24(12):1457-72.

29. Marino-Sanchez FS, Alobid I, Cantellas S, Alberca C, Guilemany JM, Canals JM, et al. Smell training increases cognitive smell skills of wine tasters compared to the general healthy population. The WINECAT Study. Rhinology. 2010;48(3):2736.

30. Mullol J, Alobid I, Marino-Sanchez F, Quinto L, de Haro J, Bernal-Sprekelsen $M$, et al. Furthering the understanding of olfaction, prevalence of loss of smell and risk factors: a population-based survey (OLFACAT study). BMJ Open. 2012;2(6):e001256.

31. Liu G, Zong G, Doty RL, Sun Q. Prevalence and risk factors of taste and smell impairment in a nationwide representative sample of the US population: a cross-sectional study. BMJ Open. 2016;6(11):e013246.

32. Sorokowska A, Schriever VA, Gudziol V, Hummel C, Hahner A,

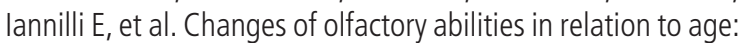
odor identification in more than 1400 people aged 4 to 80 years. Eur Arch Otorhinolaryngol. 2015;272(8):1937-44.

33. Dzaman K, Zielnik-Jurkiewicz B, Jurkiewicz D, Molinska-Glura M. Test for screening olfactory function in children. Int J Pediatr Otorhinolaryngol. 2013;77(3):418-23.

34. Wang YY, Chang RB, Allgood SD, Silver WL, Liman ER. A TRPA1-dependent mechanism for the pungent sensation of weak acids. J Gen Physiol. 2011;137(6):493-505.
35. Hucke Cl, Pacharra M, Reinders J, van Thriel C. Somatosensory Response to Trigeminal Stimulation:A Functional Near-Infrared Spectroscopy (fNIRS) Study. Sci Rep. 2018;8(1):13771.

36. Cometto-Muniz JE, Cain WS, Abraham MH. Nasal pungency and odor of homologous aldehydes and carboxylic acids. Exp Brain Res. 1998;118(2):180-8.

37. Goldman WP, Seamon JG. Very long-term memory for odors: retention of odor-name associations. Am J Psychol. 1992;105(4):549-63.

38. Sorokowska A, Sorokowski P, Hummel T. Cross-Cultural Administration of an Odor Discrimination Test. Chemosens Percept. 2014;7(2):85-90.

39. Dalton P, Mennella JA, Maute C, Castor SM, Silva-Garcia A, Slotkin J, et al. Development of a test to evaluate olfactory function in a pediatric population. Laryngoscope. 2011;121(9):1843-50.

40. Hummel T, Pfetzing U, Lotsch J. A short olfactory test based on the identification of three odors. J Neurol. 2010;257(8):1316-21.

41. Jackman AH, Doty RL. Utility of a three-item smell identification test in detecting olfactory dysfunction. Laryngoscope. 2005;115(12):2209-12.

42. Mueller C, Renner B. A new procedure for the short screening of olfactory function using five items from the "Sniffin' Sticks" identification test kit. Am J Rhinol. 2006;20(1):113-6.

43. Richman RA, Wallace K, Sheehe PR. Assessment of an abbreviated odorant identification task for children: a rapid screening device for schools and clinics. Acta Paediatr. 1995;84(4):434-7.

Manuscript received May 6, 2019; accepted for publication September 10, 2019.

\section{_ Joaquim Mullol}

Unitat de Rinologia i Clinica de l'Olfacte

Servei d'Otorinolaringologia

Hospital Clínic de Barcelona

Carrer de Villarroel, 170

08036 Barcelona, Spain

E-mail: jmullol@clinic.cat

Franklin Mariño-Sánchez

E-mail: franklinmarino@gmail.com 